\title{
Simulation of stresses and contact surfaces of disk rolling cutters with the rock when sinking in mixed soils
}

\author{
Sergey Gubanov ${ }^{1, *}$, Alexander Petsyk ${ }^{1}$, and Anatoly Komissarov ${ }^{2}$ \\ ${ }^{1}$ National University of Science and Technology "MISiS", Moscow, Russia, \\ ${ }^{2}$ Federal State Budgetary Educational Institution of Higher Education "Ural State Mining University", \\ Yekaterinburg, Russia
}

\begin{abstract}
In this paper, we consider the crack propagation in the rocks during sinking depending on the distance between the cutters. Under the same conditions, the hard and soft rocks form various fracture networks that leads to uneven sinking and decrease in the efficiency of the tunneling machine. In order to study this issue, four ranges of distance between the contact surfaces and various incidence angles of the contact surface were selected. The study includes a system that is a mountain mass layout with a disk cutter the only parameter of which is the tip width or the contact width of the disk cutter with the end-type rock. Simulation of research conditions and finding a solution to the problem were performed using the Autodesk Inventor Nastran 3D simulation software.
\end{abstract}

The development of modern metropolitan cities dictates the need for a constant increase in the rate and scale of the urban underground space exploration. The high-density urban development, a large number of motor roads, massive deployment of underground utilities for various purposes significantly complicate the new underground construction process. Such structures are extremely important for the functioning and development of large cities, including the subways, road and railway tunnels, collector tunnels, underground floors of industrial buildings and civil buildings, that can consist of the underground shopping centers, underground parking lots, etc. Thus, it is advisable to build new urban underground utilities using the ditch-free techniques, since it does not cause significant harm to the urban activities. It is due to the lack of need to block the significant urban areas on the daylight surface, as in the case of open construction methods.

There are three main construction methods for the urban underground utilities using the ditch-free techniques that can be distinguished among all types of equipment: shield-driven, shearer and drilling-and-blasting. If we consider the efficiency, safety and scope of application of these methods, it becomes clear that it is most sustainable to apply the shielddriven construction method for the urban underground utilities.

The experience has shown that at present, the most common method is the shield-driven construction of the urban underground utilities, when the mechanized rotary type tunneling

\footnotetext{
* Corresponding author: sg.gubanov@yandex.ru
} 
systems are used. Despite the rather high perfection of the shield-driven construction technology for the urban underground utilities using the rotary type systems, there is a need for more research works aimed at further development of this type of equipment. This is due to the fact that such equipment is quite expensive, as well as the fact that it is operated in very harsh conditions.

During the tunnel construction, various geological conditions are encountered that have a great influence on the operation of the tunneling machine. The properties of rocks, intrastratal stress, and the location of the disk rolling cutters have a great influence on the tunneling efficiency $[1,3,5,10]$.

As a rule, the double disk rolling cutters are installed on the modern models of rotary type tunneling systems. This phenomenon can be explained by the fact that when installing the double cutter with a small setting increment between two cracks in the rock, the cleavage occurs, as a result of which there is a more efficient rock mass destruction due to the fact that the stress areas in the rock from each of the cutters are intersecting (Fig. 1, b), whereas when using a single cutter, the insipient stress area is much smaller (Fig. 1, a). It is worth noting that this kind of analysis contains a significant number of assumptions. For a more detailed analysis of stresses and contact surfaces of the disk rolling cutters with the rock when sinking in mixed soils, the Autodesk Inventor Nastran software package was used that allows to consider a much larger set of parameters.
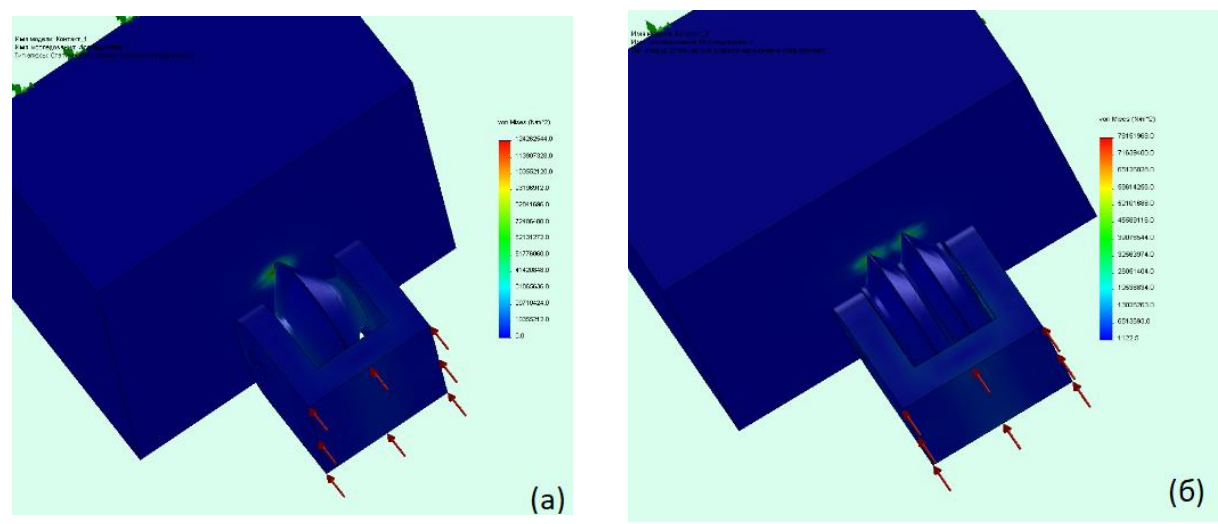

Fig. 1. Analysis of contact stresses of the cutter with the rock in the Autodesk Inventor Nastran software package.

During the production process, the fracture network is formed as a result of merging of previous and new cracks formed by pressure on the rock. The crack formation is a consequence of the fundamental forces acting in the rock. Since the fracture development contributes to the formation and propagation of the fracture network, this process should be simulated by showing the fracture development using 3D technology. In order to find a solution to this problem, the study included a system that is a mountain mass layout with a disk cutter the only parameter of which is the tip width or the contact width of the disk cutter with the end-type rock.

Figures 2, 3 demonstrate four ranges of distance between the contact surfaces with the values of $50 \mathrm{~mm}, 100 \mathrm{~mm}, 150 \mathrm{~mm}$ and $200 \mathrm{~mm}$, with various incidence angles of the contact surface with the values of $15^{\circ}, 30^{\circ}, 45^{\circ}, 60^{\circ}, 75^{\circ}$ or $90^{\circ}$, in order to perform detailed study of the distance between the contact surfaces and the stress limited direction. We simulate the crack propagation using the Autodesk Inventor Nastran software package. 


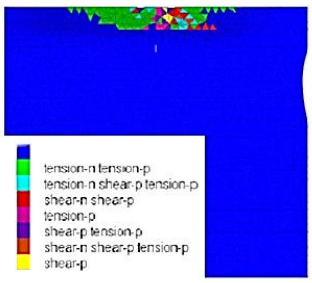

(a) $\mathrm{s}=50 \mathrm{~mm}$

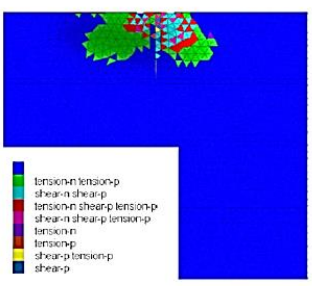

(c) $\mathrm{s}=150 \mathrm{~mm}$

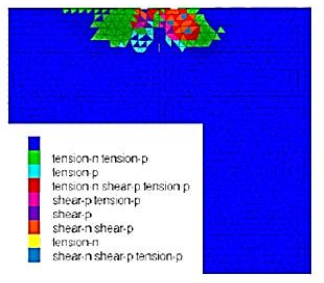

(b) $\mathrm{s}=100 \mathrm{~mm}$

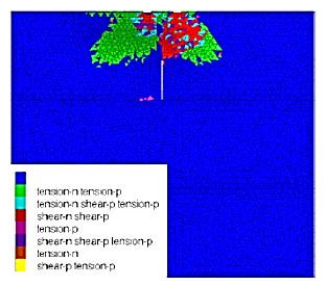

(d) $\mathrm{s}=200 \mathrm{~mm}$

Fig. 2. Stress distribution at a pitch of $60 \mathrm{~mm}$.

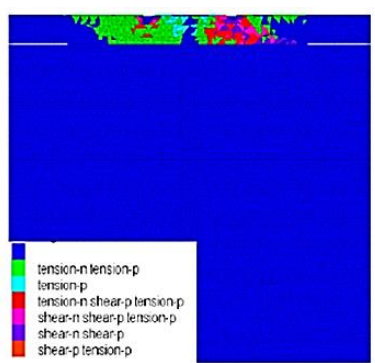

(a) $\mathrm{s}=50 \mathrm{~mm}$

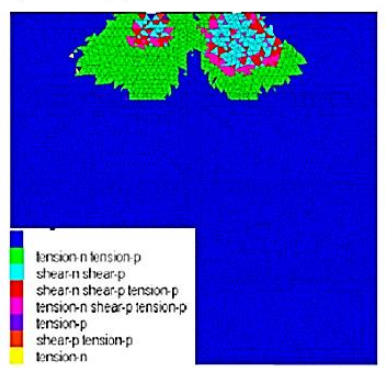

(c) $\mathrm{s}=150 \mathrm{~mm}$

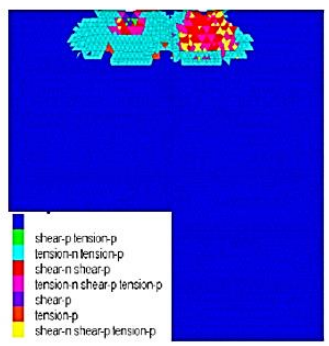

(b) $\mathrm{s}=100 \mathrm{~mm}$

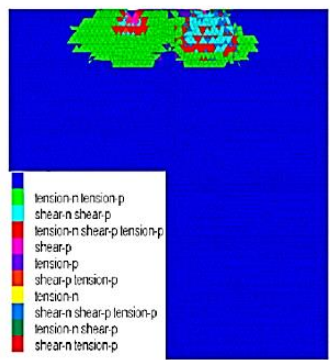

(d) $\mathrm{s}=200 \mathrm{~mm}$

Fig. 3. Stress distribution at a pitch of $140 \mathrm{~mm}$.

If we compare the data obtained, the increased stress to form cracks and rock fracture is achieved by reducing the distance between the contact surfaces. In the case of an increase in the distance between the contact surfaces, the plastic and destruction zones are expanded. It leads to an increase in cleavages that are especially visible in the soft rocks $[4,6,9]$. It should be noted that the hard and soft rocks, when they are subject to equal stress, form various fracture networks. This leads to uneven sinking and, as a consequence, a decrease in the efficiency of the tunneling machine.

The optimal angle values shall be $15^{\circ}, 30^{\circ}, 45^{\circ}, 60^{\circ}, 75^{\circ}$ or $90^{\circ}$ in the direction of the soft rock. In this case, the distance between the cutters shall be $80 \mathrm{~mm}$. Determination of 
the above values is related to the specific impact of the disc rolling cutter on a more yielding rock when forming the cleavages $[7,8]$.

Based on Figure 4, it can be noted that when the rock is exposed in the contact surface at $15^{\circ}$, the invasion zone is increased and the crushing zone is noticeable in the softer rocks.

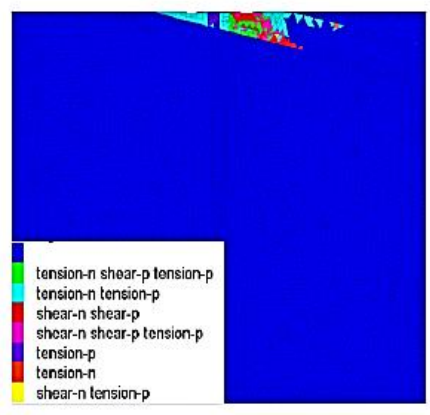

(a) $\alpha=15^{\circ}$

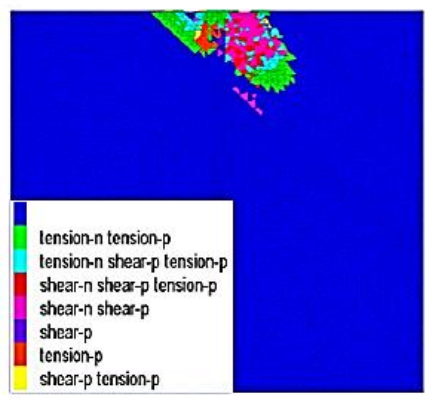

(c) $\alpha=45^{\circ}$

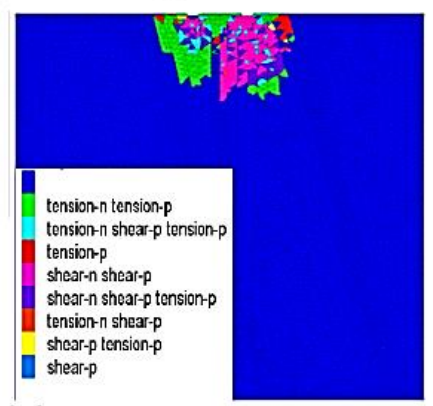

(e) $\alpha=75^{\circ}$

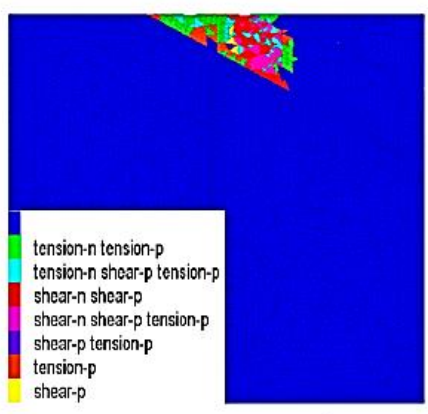

(b) $\alpha=30^{\circ}$

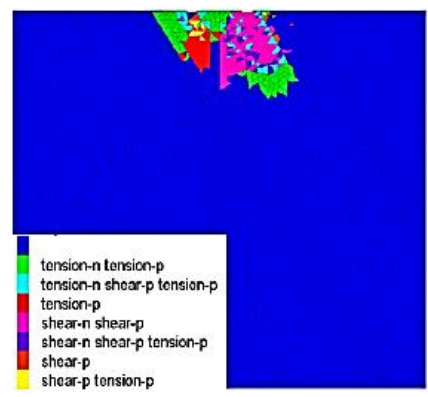

(d) $\alpha=60^{\circ}$

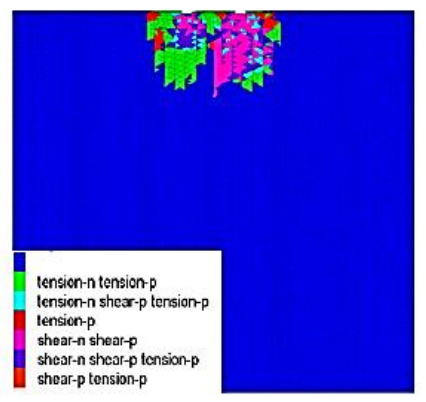

(f) $\alpha=90^{\circ}$

Fig. 4. Stress distribution when the angle of slope is changed.

Upon conducting the required studies, it was noted that the increase in the rock destruction along the exposure direction is associated with a change in the contact surface angle towards the soft rocks [2]. The fracture starting point is the contact surface plane. The large angle of the contact surface prevents the development of additional cracks in other directions. In our study, this phenomenon is explained by the relatively small distance between the contact surface and the discontinuity surface, as well as the fact that the angle between the junction plane and the sinking direction is larger. As a result of this, the rock is destructed easier, but at a small distance. 
Performance of an engineering calculation in Autodesk Inventor Nastran, allowed us to conclude that a significant increase in efficiency is possible with an optimal distance between the cutters.

In the case of the rock destruction and an increase in the distance between the contact surface with an incidence angle of $0^{\circ}$, two fragmentation modes are observed. The occurrence of two rock destruction modes is possible only if the distance between the contact surfaces with an incidence angle of $0^{\circ}$ is increased. The wider plastic and crushing zones may extend downward inside the rocks. This is especially noticeable in the case of operation in the soft rocks, since the range of the shear fracture zone is wider. In this case, the cutting efficiency is significantly increased. The rock destruction process can be controlled by the orientation of the contact surface, considering the changes in the incidence angle. The easier fracture propagation along the contact surface is affected by a smaller incidence angle of the contact surface. An increase in the limiting stress does not have a clear effect on the changes in the discontinuous fracture plastic zone in the hard rocks. However, at the same time, the discontinuous fracture range in the soft rocks varies much wider and the shear fracture propagates along the free surface and weak discontinuity surface. Such behavior leads to the absence of a sufficient number of cracks that in turn leads to a decrease in the rock fragmentation efficiency.

\section{References}

1. D.A. Yungmeyster, A.I. Isaev, Tunneling systems fitted with duplex-impact operating member for the short relieving tunnel driving with tubbing lining, Journal of Industrial Pollution Control, (2017)

2. D.A. Yungmeyster, A.I. Isaev, Rationale for the parameters of bore hammer for tunneling the service roadways in Cambrian clays, Journal of Industrial Pollution Control, (2017)

3. M.V. Secretov, Mining Information and Analytical Bulletin, 9, 81 (2018)

4. V. I. Zaykov, A.V. Bugakov, Mining Information and Analytical Bulletin, 6, 11 (1999)

5. D.Yu. Chunyuk, V.A. Kosareva, Scientific Review, 22, 53 (2016)

6. A. Khoreshok, L. Kantovich, V. Kuznetsov, E. Preis, D. Kuziev, E3S Web of Conferences (2017)

7. V.I. Klishin, B.L. Gerike, P.B. Gerike, Gornyi Zhurnal, 12, 62 (2015)

8. L.S. Aleksandrovich,, Y.D. Alekseevich, S.D. Igorevich, I.G. Adambaevich, International Journal of Applied Engineering Research, 10 (7), 16409

9. A. Afanas'Ev, D. Simisinov, V. Zubov, Materials Today: Proceedings, 19, 2358 (2019)

10. A.P. Komissarov, Yu.A. Lagunova, V.S. Shestakov, I.Yu. Ivanov, Gornyi Zhurnal, 1, 73 (2018) 